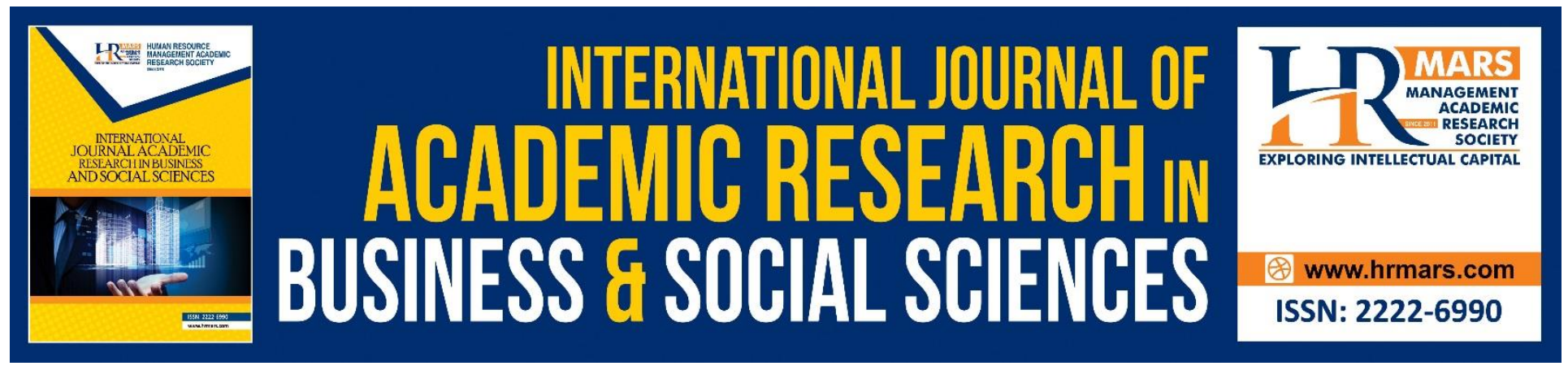

\title{
Relationship Between the Coping Factor and the Inclination to Relapse among Former Drug Addicts
}

\section{Asbah Razali}

To Link this Article: http://dx.doi.org/10.6007/IJARBSS/v8-i10/5308

DOI: $10.6007 /$ IJARBSS/v8-i10/5308

Received: 07 Oct 2018, Revised: 02 Nov 2018, Accepted: 06 Nov 2018

Published Online: 08 Nov 2018

In-Text Citation: (Razali, 2018)

To Cite this Article: Razali, A. (2018). Relationship Between the Coping Factor and the Inclination to Relapse among Former Drug Addicts. International Journal of Academic Research in Business and Social Sciences, 8(10), 1404-1416.

\section{Copyright: (C) 2018 The Author(s)}

Published by Human Resource Management Academic Research Society (www.hrmars.com)

This article is published under the Creative Commons Attribution (CC BY 4.0) license. Anyone may reproduce, distribute, translate and create derivative works of this article (for both commercial and non-commercial purposes), subject to full attribution to the original publication and authors. The full terms of this license may be seen at: http://creativecommons.org/licences/by/4.0/legalcode

Vol. 8, No. 10, 2018, Pg. 1404 - 1416

Full Terms \& Conditions of access and use can be found at http://hrmars.com/index.php/pages/detail/publication-ethics 


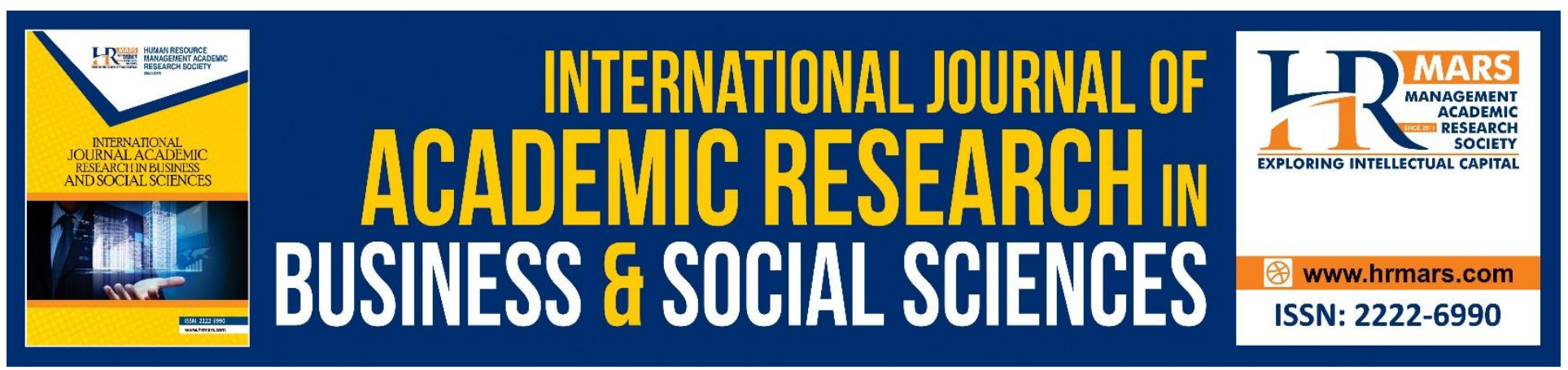

\title{
Relationship Between the Coping Factor and the Inclination to Relapse among Former Drug Addicts
}

\author{
Asbah Razali \\ University of Malaya, Malaysia
}

\begin{abstract}
Even though the government has taken many steps to overcome the drug problem among former drug addicts, this problem persists. This study aims to find out if there exists a relationship between the personal factors, which are problem-focused coping, emotion-focused coping, and evasive coping and the inclination to relapse among former drug addicts. This study involves 242 former drug addicts and utilizes the Coping Strategy Inventory (COPE) questionnaire set by Carver, Scheier \& Weintraub (1989). The Reliability Coefficient of scales utilizing the Cronbach's alpha analysis found all to be greater than .70. Studies found the level of coping for the three aspects of coping among former drug addicts are at a medium stage. Furthermore, the inferential analysis for the factors of problemfocused coping, emotion-focused coping, and evasive coping, and the inclination to relapse show the relationship strength to be between $r=.06$ and $r=.05$. This study shows the problem-focused coping, emotion-focused coping, and evasive coping factors are factors identified as related to the inclination to relapse. The positive association for the coping factors shows the existence of a positive relationship between the three coping aspects and the inclination to relapse.
\end{abstract}

Keywords: Coping Factor, Relapse, Drug Addicts, Problem-Focused Coping, Emotion-Focused Coping, and Evasive Coping

\section{Introduction}

According to a report released by the Substance Abuse and Mental Health Services Administration (SAMHSA) in 2009, more than 50 percent of drug addicts are inclined to relapse after they have completed their treatment and rehabilitation process. This situation happens due to the presence of negative effects and their inability to overcome said effects. Even though some drug addicts are able to control themselves from continuous use of drugs, there are also a number of addicts that are unable to resist the yearning for drugs. There are efforts on their part to not reuse drugs, if not for factors such as personal stress. An increase in the number of drug addicts every year is a worrying trend to all parties. This problem is not only a detriment to human capital that is part of national expectation, but it also causes government to bear crippling costs to fund treatment and rehabilitation. If these addicts are not treated, the country would possibly suffer great social and 
economic harm. However, efforts to rehabilitate former drug addicts are not easy to do as the problem of relapse among drug addicts is a cyclical phenomenon. Therefore, the issues relating to the inclination to relapse should be emphasized in order to identify the true source of their predisposition to reuse as well as aiding the government effort to tackle this persisting problem.

In the context of this study coping refers to former drug addicts' responses to their inclination to relapse. These responses include behavioral and cognitive changes seen as successful efforts to face high-risk situations. The coping in this study is measured with the COPE Inventory by Carver, Scheier \& Weintraub, (1989), which covers three dimensions: (i) problem-focused coping that focuses on efforts to solve problems (ii) emotion-focused problems that is related to emotions and (iii) evasive coping related to denial and rejection of a certain subject. Therefore, this study is specifically framed to answer the following questions:

1. What are the levels of problem-focused coping, emotion-focused coping, and evasive coping among former drug addicts?

2. How far do the problem-focused coping, emotion-focused coping, and evasive coping influence the inclination to relapse?

\section{The Problem-focused Coping Factor and the Inclination to Relapse}

According to Compas (1987), coping is any strategy or effort taken as a response to stress events. It could shape the attitudes or thoughts of any given individual. Folkman and Lazarus (1984) define coping as an individual effort to manage the situation or event beyond or exceeding level of adjustment. They opine that the link between coping and stress is a complex one. Nevertheless, coping is basically an action-oriented and intra-psychic effort to overcome, withstand, decrease, or minimize environmental and internal conflicts and urges. It is able to bring about positive effects to the individual such as reducing anxiety and increase self-satisfaction.

Frydenberg (2002) and Kiser \& Black (2005) in their studies relating to drug addict question also found they require coping to prevent the increase in risk of inclination to relapse. Breese (2005) in his study also acknowledges the lack of ability in confronting stress such as alcohol consumption and drug abuse would affect the addict's will confront problems. This situation would also affect their health and reduce their internal values. This view in line with the affirmation by Cornelius, Maisto and Pollock, (2003) that the difficulty in the behavior of drug addicts for self-control leads to their aggressive behavior, acting out of control and expectation. Those facing problems would look to other sources for support such as family, siblings, friends, or even other people that they think could help them confront their problems (Seiffge-Krenke, 2000). Nevertheless, if all these sought-for support are unachievable, they start to act out of control when faced with pressure.

For the emotion-focused coping, most previous literature state that the emotion-focused coping has a significant relationship with the inclination to relapse. Previous findings observe that the addicts would adopt emotion-focused coping when facing stress and when they found themselves deprived of social support, positive interpretation, acceptance, focus, and emotional release. The stress faced would cause the emotional inability to cope, thus leading to impulsive behavior to the detriment of 
self. The stress to the inclination to relapse drives the former addicts to continue with positive behavior and accept their lives accordingly. The importance of religion in controlling drug abuse is acknowledged by Jarusiewicz (2000) in his study exploring the relationship between the spiritual levels among former drug addicts.

Findings show the respondents with high levels of spirituality could maintain their status of being clean for up to two years compared to respondents with low levels of spirituality. This means religion and belief has a link with the self-control ability of former drug addicts from relapsing. The possibility is the presence of religious belief allows the addict to control their sad emotions, indirectly controlling themselves from relapsing. Nevertheless, previous scholars also do not deny high levels of stress and past events that could remind former addicts of drugs and shake their beliefs, leading to a challenge to their worldview and leading them to lose faith in their religion and convictions.

For the evasive coping, most previous studies also identify a link with the inclination to relapse. According to studies by Radcliffe and Stevens, (2008) this link might be caused by the addicts feeling weak and with a lack of self-control skills. They feel abandoned by people around them and are inclined to spend time with like-minded friends participating in the same activities. Some of the younger drug addicts have lax parental control. This means their leisure time is spent with friends without supervision and proper guidance from their parents and family. Most previous researchers conclude that the addicts require strategic coping skills as these skills are important in facing challenging life situations. The stress faced would not only increase the inclination to relapse, but also contribute to psychological problems such as suicide, depression, and illness. Therefore, they require coping strategy to endure internal pressure. Finally, Compas (1987) in his study also agrees that evasive coping could control and overcome threats and challenges caused by stress. It is also able to bring about positive effects for the former addicts to reduce and fight their desire to relapse. This is because evasive coping includes individual responses involving internal and external pressures. These responses accounts for behavioral and cognitive changes seen as successful efforts to face stress.

\section{Materials and Methods}

The population in this research consists of addicts that just finished their treatment and recovery at the CCRC within one to six months as most previous studies found their inclination to relapse to occur within one to six months after ending their treatment and recovery period. Cluster sampling is a sampling technique whereby all units within the cluster would be chosen. This means after cluster selection, all units within said cluster would be chosen as the study respondents. Four CCRCs were clustered according to zones, which are the Northern, Southern, Central, and Eastern Zones, representing the population in this study. This means only four CCRCs were selected as research cluster. Table 1 shows the four CCRCs selected based on cluster sampling. 
INTERNATIONAL JOURNAL OF ACADEMIC RESEARCH IN BUSINESS AND SOCIAL SCIENCES

Vol. 8, No. 10, Oct. 2018, E-ISSN: 2222-6990 @ 2018 HRMARS

Table 1: Sample Grouping Clusters Sampling of 4 Cure and Care Rehabilitation Centre (CCRC)

\begin{tabular}{l|c|c|c}
\hline Number & $\begin{array}{c}\text { Cure and Care Rehabilitation Centre } \\
\text { (CCRC) }\end{array}$ & Population & $\begin{array}{c}\text { Sampel Grouping } \\
\text { Clusters }\end{array}$ \\
\hline 1. & CCRC Rawang, Selangor & 70 & $\mathrm{n} 1=70$ \\
2. & CCRC Tampoi, Johor Bahru & 75 & $\mathrm{n} 2=75$ \\
3. & CCRC Bukit Mertajam, Pulau Pinang & 65 & $\mathrm{n} 3=65$ \\
4. & CCRC Kota Bharu, Kelantan & 75 & $\mathrm{n} 4=70$ \\
\hline \multicolumn{2}{c}{ Total N $\mathrm{N}=400$} \\
\hline
\end{tabular}

Measuring Tool and Scoring: This questionnaire contains three dimensions, which are (i) problemfocused coping (ii) emotion-focused sampling and (iii) evasive coping. The answers to each item for the questionnaire are in a likert scale with 1=Strongly disagree 2=Disagree 3=Agree 4=Strongly agree. An example of the items used for the coping scale are as such:-

(i) Problem-focused Coping

"I did what I should do"

"I immediately take action to overcome the problem"

"I focus all efforts to solve a problem"

(ii) Emotion-focused Coping

"I try to speak to someone of my feelings"

"I discover something good and positive from whatever has happened"

"I try to see from a different perspective so it may seem more positive"

(iii) Evasive Coping

"I reduce the number of efforts to solve the problem"

"I say to myself that it never happened"

"I do not continue with the effort to get what I want

\section{Result}

Levels of Problem-based Coping, Emotion-based Coping, and Evasive Coping: To measure the levels of coping, researchers have divided the coping variables to three levels, which are (1) low level, (2) medium level (3) high level. This division is also based on the mean cumulative scoring based on the five likert scale of (1) Strongly disagree (2) disagree (3) Uncertain (4) agree (5) Strongly agree. The coping factors cover three dimensions, which are problem-focused coping, emotion-focused coping, and evasive coping among former drug addicts. Table 4.0 shows data related to coping among former drug addicts based on the three dimensions. 
INTERNATIONAL JOURNAL OF ACADEMIC RESEARCH IN BUSINESS AND SOCIAL SCIENCES

Vol. 8, No. 10, Oct. 2018, E-ISSN: 222 2-6990 @ 2018 HRMARS

Table 2: Coping Among Former Drug Addicts Based on the Three Dimensions Coping Strategies

\begin{tabular}{lcccc}
\hline Coping Strategies & Frequently & Percentage & Min & Sd \\
\hline Problem-based Coping & & & & \\
Low $(1.00-2.33)$ & 32 & 13.2 & & \\
Moderate $(2.34-3.66)$ & 169 & 69.8 & 3.69 & .247 \\
High $(3.67-5.00)$ & 41 & 17.0 & & \\
& & & & \\
Emotion-based Coping & 35 & 14.5 & & .274 \\
Low $(1.00-2.33)$ & 172 & 71.0 & 3.70 & \\
Moderate $(2.34-3.66)$ & 35 & 14.5 & & \\
High $(3.67-5.00)$ & 17 & 7.0 & & \\
& 181 & 74.8 & 3.74 & .366 \\
Evasive Coping & 44 & 18.2 & & \\
Low $(1.00-2.33)$ & & & & \\
Moderate $(2.34-3.66)$ & & & \\
High $(3.67-5.00)$ & &
\end{tabular}

Table 2 shows the frequency distribution on the three coping dimensions answered by respondents. Findings for evasive coping show the highest mean score of 3.74 and standard deviation of .366. 17 respondents $(7.0 \%)$ record a low level, 181 respondents $(74.8 \%)$ have medium evasive coping, while 44 respondents $(18.2 \%)$ are at a high level. Therefore, results show the majority of respondents have evasive coping at a medium-level. The emotion-focused coping record he second highest mean score. The mean overall value for emotion-focused coping recorded in this study is 3.70 with standard deviation of .274 .172 respondents (71\%) are at a medium level, while respondents with high and low levels show the same result of 35 respondents (14.5\%) each.

Analysis results found the mean score for problem-focused coping is 3.69 with standard deviation of .243. Findings show 32 respondents (13.2\%) are at a low level, while 169 (69.8\%) respondents are at a medium level of problem-focused coping. The remaining 41 respondents (16.9\%) are at a high level. Overall, there is no significant mean difference among the three coping scales and all were around $3.69-3.74$.

Findings show the problem-focused coping record the highest level compared to emotion-focused coping and evasive coping. According to Wimbarti (2002) even though drug addicts use problemfocused coping, they do not know how to manage problem faced due to lack of self-control and failure to plan to prevent continued use of drugs. They are unable to act and take the self-initiative to escape the problem of drugs (Simpson \& Marsh, 1986). It is unsurprising the problem-focused coping records a high level compared to emotion-focused coping and evasive coping. Evasive coping is also seen at a high level.However, emotion-focused coping are at a low level. According to Sinha, (2001) drug addicts are inclined to use emotion-focused coping when faced with stress. This is 
INTERNATIONAL JOURNAL OF ACADEMIC RESEARCH IN BUSINESS AND SOCIAL SCIENCES

Vol. 8, No. 10, Oct. 2018, E-ISSN: 2222-6990 ㄷ 2018 HRMARS

because they are prone to sadness, emotional, express their feelings and aware of their problems. It is possible that the low level of emotion-focused coping leads them to be more prone to giving up.

Table 3: Problem-Focused Coping, Emotion Focused Coping, Evasive Coping and the Inclination to Relapse

\begin{tabular}{lcccc}
\hline \multicolumn{1}{c}{ Variable } & $\mathbf{Y}$ & $\mathbf{X}_{\mathbf{1}}$ & $\mathbf{X}_{\mathbf{2}}$ & $\mathbf{X}_{\mathbf{3}}$ \\
\hline $\mathrm{Y}$ (Inclination to Relapse) & 1 & & & \\
$\mathrm{X}_{1}$ ( Problem-Focused Coping) & $.566^{* *}$ & 1 & & \\
$\mathrm{X}_{2}$ ( Emotion Focused Coping) & $.564^{* *}$ & $.530^{* *}$ & 1 & \\
$\mathrm{X}_{3}$ (Evasive Coping) & $.652^{* *}$ & $.610^{* *}$ & .526 & 1 \\
\hline
\end{tabular}

\section{Relationship between Problem-Focused Coping Factor and the Inclination to Relapse}

Study results show a significant positive relationship between problem-focused coping and the inclination to relapse. The relationship strength found is medium $(r=.566, p<.05)$. Therefore, based on results, this finding rejects the first null hypothesis ( $\mathrm{HO1}$ ) that predicts no significant relationship between problem-focused coping and inclination to relapse. Accordingly, this findings is in line with previous studies (such as Frydenberg, 2002; Kiser and Black, 2005) that found the problem-focused coping provides a risk to former drug addicts and they require active strategy to take action in order to prevent the increase in the risk of inclination to relapse. This situation also affects their health and reduce internal values.

The findings also support a number of previous studies such as (Dos Santos, Rataemane, Fourie and Trathen, 2010) that reports a risk of increase in inclination to relapse among drug addicts due to lack of effective problem-focused coping strategy when they undergo stress and high risk situations. It is unsurprising there is a relationship between problem-focused coping and the inclination to relapse as each addicts has the potential to relapse as they apply various coping strategies and part of their coping involves aggressive behaviour and fear.

Meanwhile, according to Flynn et al., (2003) and Scott, Foss and Dennis (2005) addicts realise their actions flow against societal norms but they are willing to do anything to fulfil their self-indulgence without consideration for cause and effect of their actions. This view is consistent with the explanation by Hser et al., (2007) and White (2007) that addict behaviour of difficulty in self-control cause them to act aggressively, out of control and expectations. Therefore, in this study, even though studies found addicts equipped with a coping strategy, they are unable to resist desire and need to reuse. They are unable to take action and self-initiative to prevent themselves from being involved in drug problems (Simpson \& Marsh, 1986; White, 2008).

Relationship between Emotion-focused Coping Factor with the Inclination to Relapse: Results show a significant positive relationship between emotion-focused coping and the inclination to relapse. The relationship strength recorded is medium $(r=.564, p<.05)$. Therefore, based on results, the finding rejects the second null hypothesis $(\mathrm{HO2})$ that predicts no significant relationship between emotion- 
focused coping and inclination to relapse. This is acknowledged by previous researchers such as Sinha (2001) that state there is positive relationship between emotion-focused coping and inclination to relapse among former drug addicts. Furthermore, according to Sinha, former addicts use emotionfocused coping to express their feelings of the problems they are facing.

In this situation, most previous studies support the findings showing that emotion-focused coping has a significant relationship with the inclination to relapse. Specifically, this finding shows emotionfocused coping (such as access to social support, positive interpretation, acceptance, focus, and emotional release). Previous studies state that drug addicts use emotion-focused coping when they face stress. In line with the perspective of prevention of recurrence Marlatt and Gordon (1985) suggests individuals without emotion-focused coping would be more inclined to have negative effects in facing stress. The inability to react effectively could cause the inclination to relapse to be higher. Even though this model links emotional pressure with inclination to relapse as mentioned by Sinha (2001) and with empirical evidence to support this link, high emotion-focused coping could also cause the inclination to relapse.

The importance of religion in controlling drug abuse is also acknowledged by Jarusiewicz (2000) in his study that explores the relationship between levels of spirituality among former drug addicts. Results found respondents with high levels of spirituality remain clean for two years compared to respondents with low levels of spirituality. This means religion and belief is linked to addict selfcontrol and prevention of relapsing. They succeed in maintaining themselves for two years. There is possibility of religious beliefs helping addicts control their sad emotions and indirectly preventing them from relapsing.

In addition, previous researchers do not deny that high levels of stress and presence of past events reminding addicts of drugs would shake their faith and affect their worldview, leading them to lose faith in religion and conviction.

This risky situation could also turn them to give up more easily (Eliason, Amodia \& Cano, 2006). It is likely the respondents in this study have less religious conviction that inclines them towards relapsing even though they have high emotion-focused coping. Therefore, the high or low levels of religious conviction should be considered as a mediating factor between inclination to relapse and emotionfocused coping. This I because they are unable to take action and self-initiative to prevent their problems with drugs thus increasing their inclination to relapse (Walsh, Craik \& Price, 2000). This decision indirectly proves that former drug addicts with stronger religious convictions could control themselves from any stress that could lead to the risk of drug reuse.

\section{Relationship between Evasive Coping and the Inclination to Relapse}

Results show a significant positive relationship between evasive coping and inclination to relapse. The relationship strength is medium $(r=.652, p<.05)$. Therefore, based on results, this finding rejects the third null hypothesis ( $\mathrm{HO3}$ ) that predicts no significant link between evasive coping and inclination to relapse. Based on correlation analysis, results found significant positive relationship between inclination to relapse and evasive coping. Relationship strength recorded is at a medium level. 
Consistent with this, a number of previous researchers such as (Frydenberg, 2002; Kiser \& Black, 2005; Wadworth and Berger, 2006) state that when former addicts face any form of stress, they require repetitive coping and coping strategies used must be positive in order to face such stresses. The evasive coping strategy also includes severance of behaviour, mental severance, denial responses, and severance from substance. Severance of behaviour covers not trying, no effort, easily giving up, and stop trying. Examples for mental severance moves to work or other activities, spending time by watching television or films, daydreaming, or sleeping. Denial responses involve the addicts denying they even have a problem, assumes the nonexistence of problems, saying the problems faced are false and acting as if their problems never happened. This causes the relationship between evasive coping and with inclination to relapse among former drug addicts.

Explanation of this situation could possibly be seen from the perspective of their difficulty in controlling their desire for drugs that then expose them to inclination to relapse. Pack et al., (2005) state the inclination to relapse increase fivefold if former addicts are unable to control and prevent themselves from being involved in risky behaviour. In fact, drug addicts that do not effectively use coping strategies were found to have increased their risk of drug reuse by 16 times more. The study concludes that coping has a link with the inclination to relapse. Furthermore, proper use of evasive coping s described as one strategy of behavioural problem prevention among adolescents.

Furthermore, most studies conclude that addicts require coping strategy skills as these skills are important in facing challenging life situations, especially with their desire for drugs. In this situation, results seem to support Compas (1987) that evasive coping could control and manage threats and challenges due to stress. It is also able to bring about positive effects for former addicts. In this study, even though results found addicts have a medium coping strategy, they are unable to resist desires and need that leads them to relapse. In addition, addicts are unable to evade from dependence on drugs due to lack of coping when faced with problems, not looking for social support, not positively valuing self, and without self-approach to avoid drug problems.

\section{Conclusion}

In summary, results found a positive relationship for the three coping factors and the inclination to relapse. This means the higher the coping, the higher the inclination to relapse. Therefore, this result shows the problem-focused coping, emotion-focused coping, and evasive coping factors are identified as having relationship with the inclination to relapse. Positive relationship for coping factors show presence of positive relation between the three coping aspects and the inclination to relapse. In conclusion, this result shows that problem-focused coping, emotion-focused coping, and evasive coping factors are identified as having a high relationship with the inclination to relapse.

\section{Acknowledgement}

To those who directly and indirectly contributed in this paper, your kindness means a lot to me. Thank you very much. 
INTERNATIONAL JOURNAL OF ACADEMIC RESEARCH IN BUSINESS AND SOCIAL SCIENCES

Vol. 8, No. 10, Oct. 2018, E-ISSN: 2222-6990 ㄷ 2018 HRMARS

\section{Corresponding Author}

Asbah Razali, University of Malaya (UM), Malaysia, Email: asbahrazali@um.edu.my, Department of Anthropology and Sociology, Faculty of Art and Social Sciences, University of Malaya, 50603 Kuala Lumpur.

\section{References}

Breese, G.R. (2005). Stress enhancement of craving during sobriety and the risk of relapse. Alcoholism: Clinical and Experimental Research, 29: 185-195.

Brown, M. Z., Comtois, K. A., \& Linehan, M. M. (2002). Reasons for suicide attempts and nonsuicidal self-injury in women with borderline personality disorder. Journal of Abnormal Psychology, 111, 198202.

Carver, C.S., Scheier, M.F \& Weintraub, J.K. (1989). Assessing Coping Strategies: A Theoretically Based Approach. Journal of Personality and Social Psychology.56, (2), 267-283.

Compas, B.E. (1987). Coping with stress during childhood and adolescence. Psychological Buletin. 101 , No. 3, 393-403.

Cornelius, J. R., Maisto, S. A., \& Pollock, N. K., (2003). Rapid relapse generally follows treatment for substance use disorders among adolescents. Addictive Behaviors, 28(2), 381-386.

Dos Santos, M., Rataemane, S., Fourie, D. \& Trathen, B. (2010). An approach to heroin use disorder intervention within the South African context: A content analysis study. Substance Abuse Treatment, Prevention, and Policy, 5, 13. dos Santos, M. \& Van Staden, F. (2008). Heroin dependence recovery. Journal of Psychology in Africa, 18, 327-338.

Eliason, M., Amodia, D., \& Cano, C. (2006). Spirituality and Alcohol and Other Drug Treatment: The Intersection with Culture. Alcoholism Treatment Quarterly,24(3),121-141.

Finney, J. W., \& Moos, R. H. (1991). The long-term course of treated alcoholism: I. Mortality, relapse and remission rates and comparisons with community controls. Journal of Studies on Alcohol, 52, 4454.

Finney, J. W., \& Moos, R. H. (1995). Entering treatment for alcohol abuse: A stressand coping model. Addiction, 90, 1223-1240.

Flynn, P. M., Joe, G. W., Broome, K. M., Simpson, D. D., \& Brown, B. S. (2003). Recovery from opioid addiction in DATOS. Journal of Substance Abuse Treatment, 25(3),177-186.

Folkman, S. \& Lazarus, R.S (1984). Coping and adaptation. Dlm. Gentry, W. (pnyt.), Handbook of Behavioral Medicine: 44-68. New York: Basic Books Inc. 
INTERNATIONAL JOURNAL OF ACADEMIC RESEARCH IN BUSINESS AND SOCIAL SCIENCES

Vol. 8, No. 10, Oct. 2018, E-ISSN: 2222-6990 ㄷ 2018 HRMARS

Frydenberg, E. (2002). Adolescent well-being. Building young people's resources. In Frydenberg, E. \& Lewis, R. (Eds.), Beyond coping. Meeting goals, visions and challenges. Oxford: Oxford University Press.

Greenfield, S., Hufford, M., Vagge, L., Muenz, L., Costello, M., \& Weiss, R. (2000). The relationship of self-efficacy expectancies to relapse among alcohol dependent men and women: A prospective study. Journal of Studies on Alcohol, 61, 345-351.

Greenfield, S.F., Brooks, A.J., Gordon, S.M., Green, C.A., Krop, F., \& McHugh, R.K. (2007). Substance abuse treatment entry, retention, and outcome in women: A review of the literature. Drug and Alcohol Dependence.86(1):1-21.

Holahan, C.J., Moos, R.H., Holahan, C.K., \& Brennan, P. (1997) Social context, coping strategies, and depressive symptoms: an expanded model with cardiac patients. Journal Personality Social Psychology. 72,918-928.

Hser, Y., Evans, E., Huang, D., \& Anglin, D. M. (2004). Relationship between drug treatment services, retention, and outcomes. Psychiatric Services,55,767-774.

Hser, Y., Longshore, D., \& Anglin, M. (2007). The Life Course Perspective on Drug Use: A Conceptual Framework for Understanding Drug Use Trajectories. Evaluation Review, 31(6), 515-547.

Ilgen, M., McKellar J., \& Tiet Q. (2005). Abstinence self-efficacy and abstinence 1 year after substance use disorder treatment. Journal of Consulting and Clinical Psychology,73,1157-1180.

Jarusiewicz, B. (2000). Spirituality and addiction: Relationship to recovery and relapse. 18(4), 99-109.

Kellogg, S. (1993). Identity and recovery.Psychotherapy,30, 235-44.

Kiser, L.J \& Black, M.M. (2005). Family processes in the midst of urban poverty: what does the trauma literature, tell us? Department of Psychiatry, School of Medicine. Baltimore United State of America: University of Maryland.

Laudet, A. B. (2009). What does recovery mean to you? Lessons from the recovery experience for research and practice. Journal of Substance Abuse Treatment, 33, 243-256.

Linehan, M. M. (1993). Cognitive Behavioral Treatment of Borderline Personality Disorder. New York: Guilford Press.

Marlatt \& J. R. Gordon (1985). Relapse prevention: Maintenance strategies in the treatment of addictive behaviors (pp. 280-350). New York: Guilford Press.

Marlatt, G. A. (1985). Relapse prevention: Theoretical rationale and overview of the model. In G. A. Marlatt \& J. R. Gordon (Eds.), Relapse prevention: Maintenance strategies in the treatment of addictive behaviors (pp. 3-70). New York: Guilford Press. 
INTERNATIONAL JOURNAL OF ACADEMIC RESEARCH IN BUSINESS AND SOCIAL SCIENCES

Vol. 8, No. 10, Oct. 2018, E-ISSN: 2222-6990 ㄷ 2018 HRMARS

Mclntosh, J. \& McKeganey, N. (2000). Addicts' narratives of recovery from drug use: constructing a non-addict identity. Social Science \& Medicine, 50, 1501-1510.

McKay, J. R., Alterman, A I., Koppenhaver, J. M., Mulvaney, F. D., Bovasso, G. B., \& Ward, K. (2001). Continuous, categorical, and time to event cocaine use outcome variables: Degree of intercorrelation and sensitivity to treatment group differences. Drug and Alcohol Dependence, 62, 19-30.

McKay, J.R., Alterman, A.I., McLellan, A.T., \& Snider, E. (1994). Treatment goals, continuity of care, and outcome in a day hospital substance abuse rehabilitation program. American Journal of Psychiatry, 151, 254-259.

Niaura, R.S., Rohsenow, D.J., Binkoff, J.A., Monti, P.M., Abrams, D.A., \& Pedraza, M., (2008). The relevance of cue reactivity to understanding alcohol and smoking relapse. Journal of Abnormal Psychology,97:133-152.

Pack, R., Krishnamurthy, G., Cottrell, L., Stanton, B., D' Alessandri, D. \& Burns, J. (2005). Caregiver predictors of adolescent inhalant abuse in rural Applalachia. American Journal of Health Behavior, 29(4),331-241.

Pardini, D. A., Plante, T. G., Sherman. A., \& Stump. J. E. (2000). Religious faith and spirituality in substance abuse recovery: Determining the mental health benefits. Journal of Substance Abuse Treatment, 19, 347-354.

Radcliffe, P. \& Stevens, A. (2008). Are drug treatment services only for 'thieving junkie scumbags'? Drug users and the management of stigmatised identities. Social Science and Medicine, 67, 1065-73.

Ross, H. E., Lin, E., \& Cunningham, J. (1999). Mental health service use: A comparison of treated and untreated individuals with substance use disorders in Ontario. Canadian Journal of Psychiatry, 44, 570-577.

Scott, C.K., Dennis, M.L., \& Foss, M.A. (2005). Utilizing recovery management checkups to shorten the cycle of relapse, treatment reentry, and recovery. Drug and Alcohol Dependence,78, 325-338.

Scott, C.K., Foss, M.A., \& Dennis, M.L. (2005). Pathways in the relapse treatment recovery cycle over 3 years. Journal Substance Abuse Treat;28,63-72.

Seiffge-Krenke I., (1995). Stress, coping and relationships in adolescence. Hillsdale, New York: Lawrence Erlbaum.

Simpson, D. D., Joe, G. W., \& Broome, K. M. (2002). A national 5-year follow-up of treatment outcomes for cocaine dependence. Archives of General Psychiatry, 59(6), 539-544. 
INTERNATIONAL JOURNAL OF ACADEMIC RESEARCH IN BUSINESS AND SOCIAL SCIENCES

Vol. 8, No. 10, Oct. 2018, E-ISSN: 2222-6990 ㄷ 2018 HRMARS

Sinha, R. \& Li, C.S. (2007). Imaging stress and cue induced drug and alcohol craving: association with relapse and clinical implications. Drug and Alcohol Review, 26, 25-31.

Sinha, R. (2001). How does stress increase risk of drug abuse and relapse? Psychopharmacology, 158, 343-359.

Stimson, G.V., \& Oppenheimer, E., (1982). Heroin Addiction: Treatment and Control in Britain. London: Tavistock.

Substance Abuse and Mental Health Services Administration [SAMSHA] (2014). Results from the 2008 National Survey on Drug Use and Health: National Findings (Office of Applied Studies, NSDUH Series H-36, HHS Publication No. SMA 09-4434). Rockville, MD.

Swora, M. G. (2004). The rhetoric of transformation in the healing of alcoholism: The twelve steps of Alcoholics Anonymous. Mental Health, Religion, and Culture,7(3),187- 209.

Verdejo, G.A., (2007). Negative emotiondriven impulsivity predicts substance dependence problems. Drug Alcohol Dependance, 91, 213-219.

Wadsworth, M.E., \& Berger, L.E. (2006). Adolescent coping with poverty-related family stress: prospective predictor of coping and psychological symptoms. Journal of Youth and Adolescent,35,(1),57-70.

Walker, D.D., Stephens R., \& Roffman R. (2011). Randomized Controlled Trial Of Motivational Enhancement Therapy With Nontreatment-Seeking Adolescent Cannabis Users: A Further Test Of The Teen Marijuana Check-Up. Psychology Addiction Behavior, 25, 474-84.

Walker, L.S., McLaughlin, F., \& Greene, J.W. (1988). Functional illness and family functioning: A comparison of healthy and somatic zing adolescents. Family Process, 27, 317-325.

Walker, LL., Henning, K., \& Krettenauer, T. (2000). Parent and peer contexts for children's moral reasoning development. Child Development,71, 1033-1048.

Warburton, H., Turnbull, P.J. \& Hough, M. (2005). Occasional and Controlled Heroin Use: Not a Problem? York: Joseph Rowntree Foundation.

White, K.R. (2007). The relationship between socioeconomic status and academic achievement. Psychological Bulletin, 91, 461-481.

Wimbarti, S. (2002). Children's aggression in Indonesia: the effect of culture, familial factors, peers, television violence viewing and temperament. University Southern California. 